\title{
A conceptual framework for designing micro electrical connectors for hearing aid instruments
}

Doagou Rad, Saeed; Islam, Aminul; Fuglsang-Philip, M.

\section{Published in:}

Proceedings of the 11th International Conference on Multi-Material Micro Manufacture (4M2016) : co-organised with 10th International Workshop on Microfactories (IWMF2016)

Publication date:

2016

Document Version

Peer reviewed version

Link back to DTU Orbit

Citation (APA):

Doagou Rad, S., Islam, A., \& Fuglsang-Philip, M. (2016). A conceptual framework for designing micro electrical connectors for hearing aid instruments. In Proceedings of the 11th International Conference on Multi-Material Micro Manufacture (4M2016) : co-organised with 10th International Workshop on Microfactories (IWMF2016) (pp. 4). Research Publishing Services.

\section{General rights}

Copyright and moral rights for the publications made accessible in the public portal are retained by the authors and/or other copyright owners and it is a condition of accessing publications that users recognise and abide by the legal requirements associated with these rights.

- Users may download and print one copy of any publication from the public portal for the purpose of private study or research.

- You may not further distribute the material or use it for any profit-making activity or commercial gain

- You may freely distribute the URL identifying the publication in the public portal 


\title{
A conceptual framework for designing micro electrical connectors for hearing aid instruments
}

\author{
S. Doagou-Rad ${ }^{1}$, A. Islam¹, M. Fuglsang-Philip² \\ ${ }^{1}$ Centre of Acoustic Mechanical Microsystems (CAMM), Technical University of Denmark, Building 352, DK-2800 \\ Kgs. Lyngby, Denmark \\ ${ }^{2}$ Oticon A/S, Kongebakken 9, 2765 Smørum, Denmark
}

\begin{abstract}
Electrical connectors play vital roles in modern electronic instruments. Hearing aid devices as advanced combinations of micro mechanics and electronics comprise various electrical connectors for different purposes. However, the current trend in the miniaturization along with the sharp technological advancements have urged them to incorporate increased number of electrical contacts. The current paper presents a conceptual framework for designing and manufacturing novel plug and socket systems for hearing aid instruments by using the state of art manufacturing technologies for micro components. These concepts have the capability of using as different connectors like RIC (Receiver In the Canal), programming and FM connection either individually or together. Various conceptual designs are provided for flexible connectors and their advantages and disadvantages are discussed in detail through different computer simulations and experiments on the 3-D printed prototypes. In fact, the presented designs not only are able to provide a range of functions for other similar micro products, but also depict an outline for the challenges in this area and the possible approach and solutions in the design of micro electrical connectors.
\end{abstract}

Keywords: Hearing aid, Conceptual design, Electrical connector, Micro components

\section{Introduction}

Recent advancements in realm of science and technology have made significant changes in the manufacturing of novel micro components. However, the current trend in the miniaturization of the electronic instruments has been accompanied with new needs and challenges. Hearing aid instruments are technological pieces of modern art incorporating novel developments in different areas of material, electronics, mechanics, and manufacturing. Since these electronic devices like other medical instruments define the functionality and the quality of many human lives remarkably, the highest performance and the least possibility of errors during the lifetime of these vital instruments are expected.

In essence, hearing aids consist of four main parts, namely, microphone, processor, receiver and power source. The microphone picks up the sounds from the environment and passes it to the processor. The processor strengthen the received signals and deliver them to the receiver. Finally, the ear canal receive the amplified signal. The digital age has transformed the different involved parts into very sophisticated components. Frequency Modulation (FM), speakers, and programming are different types of connections with different numbers of contacts that can be found in a single advanced delicate hearing aid instrument (Fig. $1(\mathrm{a})$ ). Moreover, since they act as replacements or enhancement of some complicated human functions, additional connections for different applications are expected to be added to these devices in the future [1] The purpose of this study is to construct a systematic framework for designing flexible electrical connectors comprising different number of contacts. In order to accomplish this task, a practical problem with realistic requirements and bounds from users, industry, and technology have been considered. The result of this approach was different conceptual designs of electrical connections suitable for mass production in the micro electronic product industries especially in hearing aid industries. In addition, the material selection and innovative fabrication processes for such electrical connectors will be discussed in detail.

\section{Scope of the design}

Usually, a connector is used where possible future disconnection of the subsections is desirable. Electrical contacts essentially provide the required connections between different parts of a device through metallic components of plug and socket. Electrical connection systems in hearing aids instruments just like many other electrical devices are mainly comprised of plug (male) and socket (female) parts. However, due to the minuscule size of these plugs and sockets, they are inherently different from conventional connections [2]. The new design of electrical connectors for hearing aids in this project intends to provide a modular concept in the area of hearing aids connection systems, which can provide 2-8 numbers of electrical contacts. The geometrical constraints of the mounted plug and socket are $8 \mathrm{~mm}$ in length (Max) and $5 \mathrm{~mm}$ in width (diameter). In addition, the mounting and dismounting loads should not exceed $10 \mathrm{~N}$.

Moreover, the components of the connection system should be corrosion and oxidation resistant when exposed to humidity, sun lotion and sweat. Materials should also be resistant to soldering temperature, and compliance to ROHS and REACH is also necessary, just like other medical applications. The manufacturing process should also be suitable for the mass volume production such as injection molding.

Furthermore, other parameters such as aesthetics, 
sealing behavior, locking mechanism, ease of manufacturing and assembly, lifetime, reducing the possibility of error during the use of the device are other influential factors that cannot be ignored. User friendliness also plays a major role in the hearing aids, especially due the fact that many of the users of such devices are older people. For instance, correct orientation of the connectors during mounting should be easy for all users with different physical abilities.

\section{Scope of Materials and manufacturing}

All plugs and sockets are consisted of three main parts namely housing, metal contacts, and sealing (Fig. 1 (b)). However, based on the design and the applied manufacturing method the material, shape, geometry vary in a wide range.

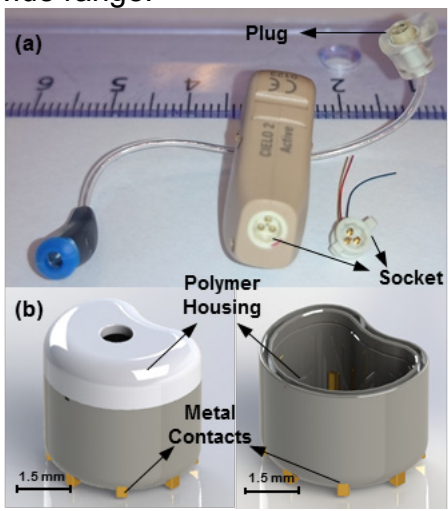

Fig. 1. (a) Plug and socket in a RIC connector (b), Schematic plug (left) and socket (right) with the corresponding polymeric and metallic parts.

Table 1 summarizes important information and specifications considered for the potential materials and manufacturing methods during the design phase. This general picture enables us to implement the contemplated novel ideas on a solid and realistic foundation. Indeed, designing and development of a medical device requires several factors to be taken into consideration. An appropriate material in medical industry must fulfill some strict criteria such as physical, mechanical, thermal, electrical, chemical, sterilization resistance, biocompatibility, and joining and welding capabilities. In addition, the range of dimensions, size, and weight of the part or product plays a critical role. Other factors that must be taken into the calculations are forces, stresses, and impact loads that the product encounters during its service life. In addition, physical properties including density, color and aesthetics, water absorption cannot be neglected. However, based on the design parameters and applied manufacturing methods, the influential parameters vary [3].

\subsection{Housing and sealing}

Polymeric housing of plugs and sockets should have acceptable mechanical properties such as tensile strength, tensile elongation, flexural strength, impact resistance, and young's modulus. The thin walls $(<500$ $\mu \mathrm{m}$ ) of the components dictate minimum values for the properties of the applied polymers. Moreover, the selected polymers are biocompatible and have a good chemical resistance to the possible presence of chemicals such as skin lotions, wax, salt, and weak acids. It is also noteworthy to mention that all the melting temperatures are higher than the soldering temperature $\left(240^{\circ} \mathrm{C}\right)$

Furthermore, in order to effectively seal plugs and sockets (according to IP 6, IP 8 standards) during the service life of the final product, which is considerably important in the design, due to their application in different environmental conditions, two main options have been considered. The first option, which is also more common, is using available standard or manufactured based on our design sealing rings and assembling them in the next step. The alternative option is using $2 \mathrm{~K}$ moulding, to manufacture the sealing elastomer simultaneously with plug or socket.

Table 1

The materials and manufacturing process

\begin{tabular}{|c|c|c|}
\hline Component & Material & $\begin{array}{l}\text { Manufacturing } \\
\text { Process }\end{array}$ \\
\hline $\begin{array}{l}\text { Plug and socket } \\
\text { housing }\end{array}$ & $\begin{array}{l}\text { PA 6,6, PEEK, } \\
\text { PPA }\end{array}$ & Injection molding \\
\hline \multirow{3}{*}{$\begin{array}{l}\text { Electrical } \\
\text { contacts }\end{array}$} & $\begin{array}{l}\text { CuNi18Zn20 } \\
\text { Silver } \\
\text { CuNi15 Silver } \\
\text { Tungsten }\end{array}$ & $\begin{array}{l}\text { Cutting, stamping } \\
\text { and } \\
\text { Machining }\end{array}$ \\
\hline & $\begin{array}{l}\text { Gold } \\
\text { Silver }\end{array}$ & Electroplating \\
\hline & $\begin{array}{l}\text { Copper-Nickel- } \\
\text { Gold }\end{array}$ & $\begin{array}{l}\text { LDS } \\
\text { LISA }\end{array}$ \\
\hline \multirow[t]{2}{*}{ Sealing } & $\begin{array}{l}\text { TPE, TPU, and } \\
\text { the standard } \\
\text { products }\end{array}$ & $\begin{array}{l}\text { Extrusion, } \\
\text { injection molding, } \\
\text { compression } \\
\text { molding }\end{array}$ \\
\hline & TPE, TPU, LSR & $\begin{array}{l}2 \mathrm{k} \text { Injection } \\
\text { molding }\end{array}$ \\
\hline
\end{tabular}

$2 \mathrm{~K}$ injection moulding consists of processing two different polymers (usually one soft and one hard) into a product by means of one injection moulding process [4]. The real benefit of $2 \mathrm{~K}$ plastic injection molding of thermoplastic materials lies in the economic area, where the two different materials can be fabricated with high speed, efficiency and economy. This process eliminates the labor-intensive secondary operations used for so many years and replaces them with highspeed automated operations, to yield a more consistent, higher quality fabricated part at a significantly lower cost. However, in order to have a prefect sealing, the two materials should be compatible to create an effective bonding at the interface. In fact, Thermoplastic elastomers (TPE) are bonded to engineering plastics by melt adhesion at the production stage and no separate adhesive is needed (Fig. 2). For instance, some commercially available products that are compatible with Nylon 6,6 are Lifoflex B045, RTP 6091-70 A, and Kraiburg TV6VNZ. The materials can also provide the required elastic and hardness properties.

(a)

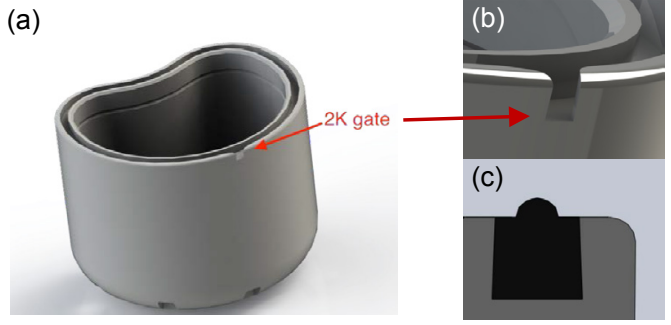

Fig. 2. (a), (b) The gate of the second shot in the $2 k$ injection molding, and (c) the inserted elastomer as the sealing. 


\subsection{Electrical contacts}

Indeed, all considerations in different elements of a connector should lead to a guaranteed electrical connection that enables all components in the system function effectively. In order to have good electrical contact, in addition to the selection of materials with high electrical conductivity (resistivity $<3.0 \times 10^{-8} \Omega . \mathrm{m}$ ), additional attention should also be payed to some other facets. Contact elements encounter different mechanical and surface loads during their life-time [5]. Tensile strength, ductility, tribological behavior, corrosion resistance are some of the parameters that should be investigated extensively in the micro contact elements (one dimension around $200 \mu \mathrm{m}$ ). Moreover, the used materials should comply with REACH and ROHS regulations. It is also noteworthy to mention that, due to micro size of the contacts in the hearing aid instruments, application of LDS (Laser Direct Structuring) process to create the circuits seems attractive (see Fig. 3). Although electrical conductivity and production speed would be affected negatively [6]

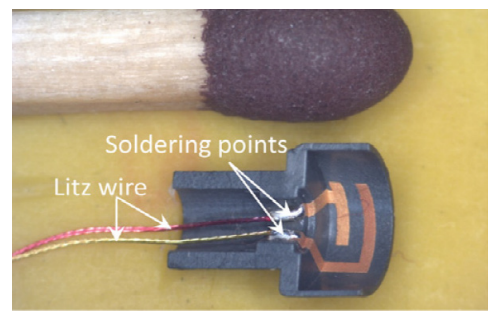

Fig. 3 LDS lines in the RIC connector. [6]

\section{Conceptual designs}

Based on the mentioned considerations, four different designs were developed for the application in the hearing aid instruments (Fig. 4). Although, all the designs comply with the requirements and deliver the eight connections, they have been designed from various point of views with different manufacturing processes.

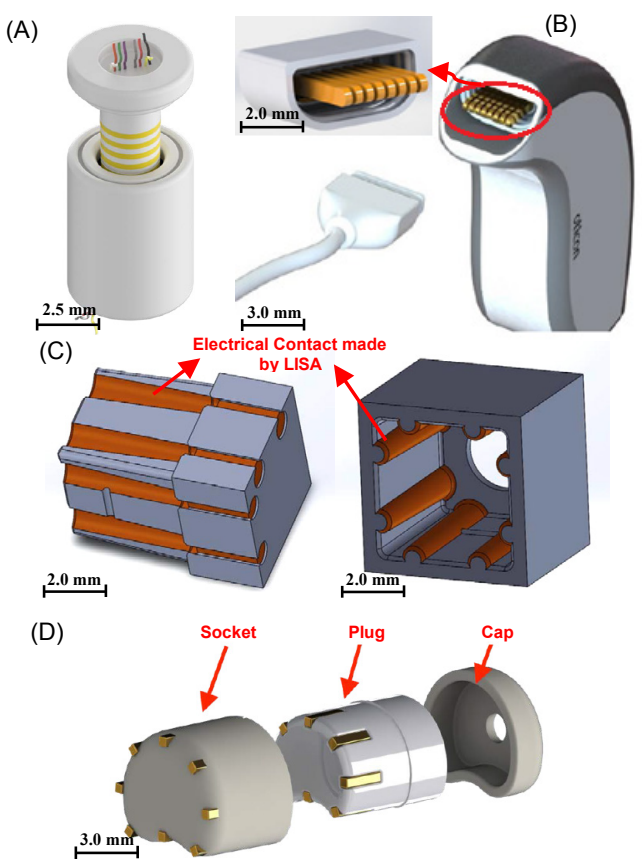

Fig. 4. The conceptual designs of four micro connectors.
The first design (Des. A) is inspired from the conventional jack-plug connection that can be found in many electronic devices, especially for audio connections. However, the design was changed fundamentally to provide eight micro contacts based on the MID (Moulded Interconnect Devices) concept. In order to produce this design, two halves are injection molded, subsequently, LDS is used to create the paths and the two sections are glued together finally (see Fig. 3). The second design (Des. B) consists of eight straight contacts in a single row. This design incorporates the application of $2 \mathrm{k}$ molding and two types of materials. The applied conductive plastics, in this design as the core of electrical elements to be electroplated either enhances the electrical conductivity, or make the electroplating to create the connections possible. The third design (Des. C) is a simple LEGO-brick like structure that uses LISA (Laser Induced Selective Activation) to create electrical connections after injection moulding of plug and socket housings. Finally, the fourth design (Des. D) uses goldcoated plates as the electrical contacts which are glued to the housings and are soldered to the wires. Moreover, the design uses $2 \mathrm{~K}$ moulding process for the sealing of the connections. Table 3 summarizes specifications to provide a general comparison between the four presented conceptual designs.

Table 3

Comparison of the four present designs

\begin{tabular}{|c|c|c|c|}
\hline $\begin{array}{c}\text { Design } \\
\text { Code }\end{array}$ & $\begin{array}{l}\text { manufacturing } \\
\text { and assembly } \\
\text { steps No. }\end{array}$ & Advantages & Disadvantages \\
\hline Des. A & $\begin{array}{l}\text { Socket: } 5 \\
\text { Plug: } 4\end{array}$ & $\begin{array}{l}\text { - Elimination } \\
\text { of the need to } \\
\text { orient plug } \\
\text { and socket to } \\
\text { mount them } \\
\text { - Flexibility }\end{array}$ & $\begin{array}{l}\text { - Difficult } \\
\text { manufacturing } \\
\text { - Less } \\
\text { electrical } \\
\text { conductivity }\end{array}$ \\
\hline Des. B & $\begin{array}{l}\text { Socket:5 } \\
\text { Plug: } 4\end{array}$ & $\begin{array}{l}\text { - Easiness in } \\
\text { orientation } \\
\text { due to the } \\
\text { shape of the } \\
\text { design }\end{array}$ & $\begin{array}{l}\text { - Difficult } \\
\text { manufacturing } \\
\text { - Possibility of } \\
\text { mechanical } \\
\text { failures in the } \\
\text { electrical } \\
\text { contact } \\
\text { elements }\end{array}$ \\
\hline Des. C & $\begin{array}{l}\text { Socket: } 4 \\
\text { Plug: } 4\end{array}$ & $\begin{array}{l}\text { - Easy } \\
\text { manufacturing } \\
\text { and assembly } \\
\text {-high flexibility }\end{array}$ & $\begin{array}{l}\text { - Less } \\
\text { electrical } \\
\text { conductivity } \\
\text { - visual need } \\
\text { to correct } \\
\text { orientation to } \\
\text { mount }\end{array}$ \\
\hline Des. D & $\begin{array}{l}\text { Socket: } 4 \\
\text { Plug: } 6\end{array}$ & $\begin{array}{l}\text { - Cannot be } \\
\text { mounted } \\
\text { wrong, while it } \\
\text { is self- } \\
\text { orienting due } \\
\text { to the shape } \\
\text { of the design } \\
\text { - Assured } \\
\text { electrical } \\
\text { connection } \\
\text { - Flexibility }\end{array}$ & $\begin{array}{l}\text { - Higher } \\
\text { number of } \\
\text { manufacturing } \\
\text { and assembly } \\
\text { steps }\end{array}$ \\
\hline
\end{tabular}

\section{Structural and molding analyses}

In order to analyze the quality of standard and $2 \mathrm{~K}$ injection molding processes, several simulations were 
conducted through the commercially available Moldflow software. In fact, the simulations provided a semirealistic overview of the actual manufacturing to see whether the contemplated design is practical or not. The appropriate location of the gate, problematic areas during the filling of the mold, and the air trap zones are some of the results of these simulations (Fig. 5(a) and $5(\mathrm{~b}))$

Furthermore, in the absence of the relevant experiments, the finite element analyses will provide acceptable estimations on how the designs are performing under possible acting loads. One of the most important outputs of these simulations is detection of the critical aspects of the designs that affect the expected function of the connectors. Structural analyses of the designs under the working loads were performed using the commercially available ANSYS software. Fig. 5(c) and 5(d) show the conducted simulations on the components of design $(A)$, and (D), respectively. The compression tests on the socket of the design (D) showed the high probability of failure during the lifetime of connector that makes the modification of the wall thickness on those areas necessary (Fig. 5(d))
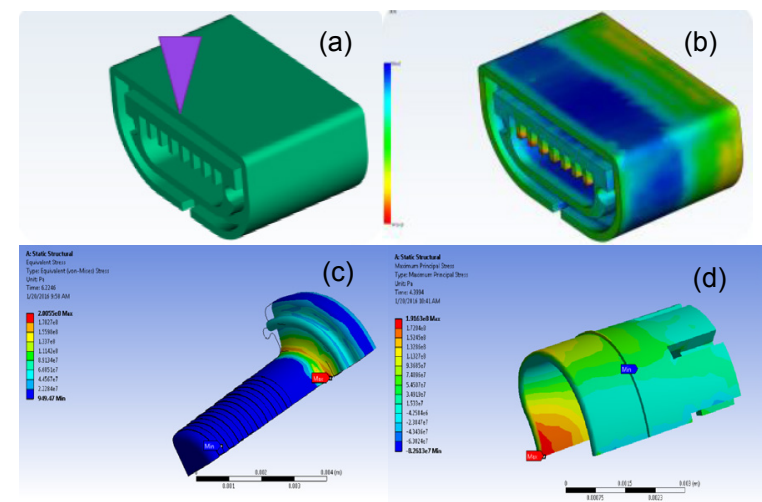

Fig. 5. Autodesk Moldflow simulations to find the suitable gate location for des. B, (a) location of the gate, (b) gating test. The Von Mises stress contour plot using ANSYS software for the components (c) des. A, (d) des. D.

\section{Prototyping}

The prototyping was performed using the EnvisionTEC $\AA 3 D$ rapid prototype manufacturing system with the application of ABFlex resin in the original and $\times 3$ scale sizes (Fig. $6(\mathrm{a})$ ). Although, the material properties of the 3-D printed prototypes were different from the targeted materials (Table 1), an acceptable estimation in the function of the designed snap-fits and dismounting forces can be measured. Subsequently, the $3 D$ printed samples were investigated by Alicona Infinite Focus and DeMeet 3D CMM to check the accuracy of the designs (Fig. 6). It is also noteworthy to mention that the printed samples were used to measure the dismounting force through simple tension experiments. The results showed 5-14 $N$ force to dismount the plug and socket based on different designed locking mechanisms.

\section{Conclusions}

Different aspects of designing and manufacturing of micro components in the advanced hearing aid instruments were investigated in detail. Influential parameters on the functionality of the products from designing, manufacturing and user point of views were incorporated in a systematic approach, which resulted into four different final products. Moreover, the application of the state of art manufacturing methods in the area of micro electrical connectors were introduced and applied in the designs effectively.

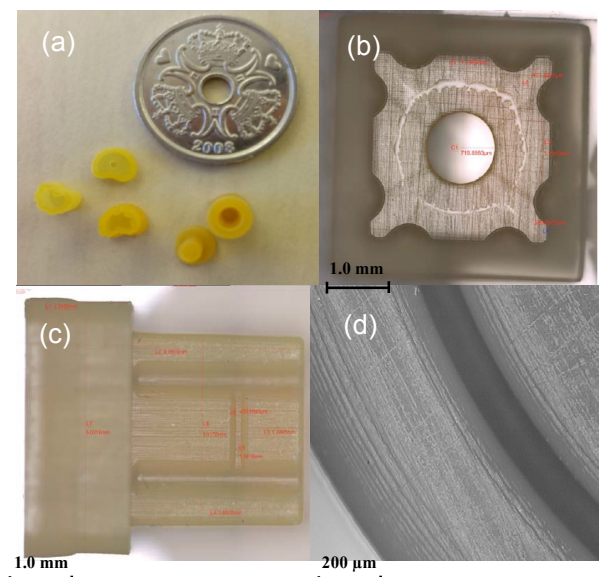

Fig. 6 (a) prototypes in comparison to Danish one-krone (b) des. C plug, snap fit grooves in (c) des. C and (d) des. A.

Although the four introduced designs meet the requirements, and can be categorized as flexible connectors, which was one of the main pillars of the considered structure, they are fundamentally different from each other. Des. A is a complete user-friendly product specifically due to simplicity in mounting and dismounting. However, the application of LDS might not be preferable due to its unfavorable declining impact on the rate of production. In addition, the electrical conductivity of the contacts should be intensely investigated due to the inherent surface cracking. Similarly, Des. B suffers from the complications of the manufacturing process. It seems Des. C and Des. D offer more beneficial parameters than the first two designs. Their manufacturing process is much easier and cheaper, especially in the case of Des. C. Moreover, the reliability during their service time is efficiently appropriate in the area of micro components.

\section{Acknowledgements}

Oticon A/S, Denmark is acknowledged for their support in the project.

\section{References}

[1] A. Islam, et al. , "8 Pin RIC Socket for Hearing Aid Applications," in Proceedings 9th International Conference on Multi Material micro Manufacture, 2012, 241-249.

[2] P. G. Slade, Electrical Contacts: Principles and Applications, Second Edition. Taylor \& Francis, 2013.

[3] V. R. Sastri, Plastics in Medical Devices. Elsevier, 2010.

[4] A. Islam, et al., "Two-component micro injection moulding for hearing aid applications," Int. J. Adv. Manuf. Technol., vol. 62, 605-615.

[5] S. Fouvry, et al. "Introduction of an exponential formulation to quantify the electrical endurance of microcontacts enduring fretting wear: Application to $\mathrm{Sn}, \mathrm{Ag}$ and Au coatings," Wear, 2011,vol. 271, 1524-1534.

[6] A. Islam, et al., "Quality investigation of miniaturized Moulded Interconnect Devices for hearing aid applications,"CIRP Ann. Manuf. Technol., 2015, 539-544. 